\title{
Penetrance of eye defects in mice heterozygous for mutation of Gli3 is enhanced by heterozygous mutation of Pax6 Paulette A Zaki ${ }^{1}$, J Martin Collinson ${ }^{2}$, Junko Toraiwa1, T Ian Simpson'1, David J Price*1 and Jane C Quinn ${ }^{1}$
}

\author{
Address: ${ }^{1}$ Genes and Development Group, University of Edinburgh, Hugh Robson Building, George Square, Edinburgh, EH8 9XD, UK and ${ }^{2}$ School \\ of Medical Sciences, Institute of Medical Sciences, University of Aberdeen, Aberdeen AB25 2ZD, UK \\ Email: Paulette A Zaki - paulettezaki@hotmail.com; J Martin Collinson - m.collinson@abdn.ac.uk; Junko Toraiwa - J.Toraiwa@sms.ed.ac.uk; T \\ Ian Simpson - Ian.Simpson@ed.ac.uk; David J Price* - David.Price@ed.ac.uk; Jane C Quinn - Jane.Quinn@ed.ac.uk \\ * Corresponding author
}

Published: 09 October 2006

BMC Developmental Biology 2006, 6:46 doi:10.1186/147|-2/3X-6-46

This article is available from: http://www.biomedcentral.com/l47I-2/3X/6/46

(c) 2006 Zaki et al; licensee BioMed Central Ltd.

This is an Open Access article distributed under the terms of the Creative Commons Attribution License (http://creativecommons.org/licenses/by/2.0), which permits unrestricted use, distribution, and reproduction in any medium, provided the original work is properly cited.
Received: 13 July 2006

Accepted: 09 October 2006

\begin{abstract}
Background: Knowledge of the consequences of heterozygous mutations of developmentally important genes is important for understanding human genetic disorders. The Gli3 gene encodes a zinc finger transcription factor and homozygous loss-of-function mutations of Gli3 are lethal. Humans heterozygous for mutations in this gene suffer Greig cephalopolysyndactyly or PallisterHall syndromes, in which limb defects are prominent, and mice heterozygous for similar mutations have extra digits. Here we examined whether eye development, which is abnormal in mice lacking functional Gli3, is defective in Gli3 $3^{+/-}$mice.
\end{abstract}

Results: We showed that Gli3 is expressed in the developing eye but that $\mathrm{Gli3}^{+/-}$mice have only very subtle eye defects. We then generated mice compound heterozygous for mutations in both Gli3 and Pax6, which encodes another developmentally important transcription factor known to be crucial for eye development. Pax6 $6^{+/-}$; $\mathrm{Gli3}^{+/-}$eyes were compared to the eyes of wild-type, Pax6 $6^{+/-}$ or $\mathrm{Gli}^{+/-}$siblings. They exhibited a range of abnormalities of the retina, iris, lens and cornea that was more extensive than in single $\mathrm{Gli}^{+/-}$or $\mathrm{Pax}^{+/}$- mutants or than would be predicted by addition of their phenotypes.

Conclusion: These findings indicate that heterozygous mutations of Gli3 can impact on eye development. The importance of a normal Gli3 gene dosage becomes greater in the absence of a normal Pax6 gene dosage, suggesting that the two genes co-operate during eye morphogenesis.

\section{Background}

The zinc-finger transcription factor Gli3 is required for normal limb, brain and eye development. In humans, a number of different mutations to the GLI3 allele can cause Greig cephalopolysyndactyly (GCPS) or Pallister-Hall Syndrome (PHS) [1,2]. Clinical features of GCPS include polydactyly, syndactyly, ocular hypertelorism and macro- cephaly; those of PHS include polydactyly, imperforate anus, renal abnormalities, hypothalamic hamartoma and pituitary dysplasia. Mutations of the Gli3 gene in mice cause the extra-toes (Xt) phenotype [3]. Johnson [4] first reported a comprehensive analysis of the developmental anatomy of $X t$ mice. Homozygotes die by birth and the most prominent defects are found in the distal limbs, in 
rostral portions of the head including the forebrain and eyes (see below), along the ventral midline of the thorax and along the midline of the visceral ectoderm. Heterozygotes are described as developing relatively normally in all respects bar the formation of an extra digit, or digit-like appendage, on either the fore- or hindlimbs.

The vertebrate transcription factors Gli1, Gl2 and Gli3 are homologues of the Drosophila transcription factor cubitus interruptus [5]. These transcription factors transduce the responses of cells to diffusible morphogens of the Hedgehog family in both vertebrates and invertebrates [6]. Although Gli3 may have an early activator function in vertebrates [7], it is thought that its main actions are to repress the expression of sonic hedgehog (Shh) target genes. Thus, loss of Gli3 in mice that also lack Shh can reverse many of the defects associated with reduced hedgehog signalling [8], presumably because loss of Gli3 allows the reactivation of Shh target genes.

With regards the requirement for Gli3 in eye development, Gli3\%-embryos exhibit a variety of eye abnormalities ranging from microphthalmia to the absence of any remnant of eye tissue $[4,7,9-11]$. Most likely these defects stem from interference with normal Shh signalling, which is essential for normal initiation of eye development [12] and later neural retinal development [13]. The extent to which a normal gene dosage of Gli3 is needed for eye development is not clear. The only eye defect described in mice heterozygous for mutations in Gli3 is the presence of folded retinae in a proportion of neonatal animals [4]. In the present study, we characterized the eye phenotype of Gli3+/- mice and identified previously undescribed defects that were subtle. We then considered whether the requirement for a normal dosage of Gli3 might be greater if the gene dosage for another transcription factor known to be critical for eye development was to be reduced.

Extensive work on Pax6 has highlighted the important role that this molecule plays in both invertebrate and vertebrate eye development [e.g. reviewed in $[14,15]]$. Mutations within the Pax6 gene cause eye abnormalities in both mouse and man $[16,17]$. Mice homozygous for null mutations in the Pax6 gene fail to form eyes $[16,18,19]$ whereas mice heterozygous for Pax6 mutations exhibit microphthalmia and have hypoplastic irises and multiple anterior segment defects [19-22]. There is evidence that Pax6 is both regulated by and regulates expression of Shh in brain tissue: Shh has been shown to repress Pax6 expression [23] and loss of Pax6 in mutant mice causes an upregulation of Shh expression [24-26]. Thus, reduction of either Pax6 or Gli3 levels might be predicted to affect eye development by activation, through different mechanisms, of Shh signalling. When we compared $\mathrm{Pax}^{+/-}$; Gli3+/- eyes to the eyes of wild-type, $\mathrm{Pax}^{+/-}$or Gli3+/- sib- lings we observed a range of abnormalities more extensive than in Gli3+/- or $\mathrm{Pax}^{+/-}$mutants or than would be predicted by addition of their phenotypes.

\section{Results \\ Overlapping expression of Pax6 and Gli3 in the developing eye}

As shown in Fig. 1A,B, Pax6 and Gli3 are expressed in the prenatal mouse eye [see also $[5,18,27,28]]$. Both genes are expressed in the neural retina, retinal pigment epithelium, lens and surface ectoderm.

\section{General development of the eye in $\mathrm{Gli3}^{+/}, \mathrm{Pax6}^{+/-}$and Gli3 ${ }^{+/-}$; Pax6+l- mutants}

The appearances of E14.5 Gli3+/-, Pax6 ${ }^{+/-}$and Gli3+/-;Pax6+/ - eyes, immunostained for Pax6 expression, are shown in Fig. 1C-E. Pax6 immunoreactivity was seen in the developing neural retina, retinal pigment epithelium, lens and surface ectoderm in all geneotypes, as in wild-types. There were, however, differences in morphology.

The E14.5 Gli3+/- eyes appeared slightly larger than those of wild-type siblings, although their appearances were otherwise normal (Fig. 1C). The E14.5 $\mathrm{PaxG}^{+/}$eyes appeared smaller than those of wild-type siblings (Fig. 1D) and Pax6 protein was seen in cells forming a lens-corneal bridge (arrowhead in Fig. 1D), as described previously [22]. The sizes of E14.5 $\mathrm{Pax}^{+/-}$; $\mathrm{Gli3}^{+/-}$eyes were more variable than those of siblings of the other three genotypes; many were similar to those of $\mathrm{Pax}^{+/-}$-eyes (Fig. 1E). $\mathrm{Pax}^{+/-;} \mathrm{Gli3}^{+/-}$eyes showed more obvious abnormalities than eyes of the other genotypes, including dysplasia at the most distal tips of the retina causing ectopic retinal tissue within the presumptive anterior chamber (Fig. 1E).

We then examined the overall mass of eyes of the different genotypes in adults (Fig. 2). Similar to previous studies [22], we found that the average mass of $\mathrm{Pax}^{+/-}$eyes (18.1 $\left.\pm 0.2 \mathrm{mg}, s d=1.0, \sigma^{2}=1.0, \mathrm{n}=24\right)$ was significantly less than that of wild-type eyes $\left(24.7 \pm 0.4 \mathrm{mg}, s d=1.8, \sigma^{2}=\right.$ $3.4, \mathrm{n}=18)(P<0.001$, Student's t-test $)($ Fig. 2$)$. The average mass of $\mathrm{Gli3}^{+/}$eyes was slightly, but significantly, larger than that of wild-type eyes $(26.1 \pm 0.3 \mathrm{mg}, s d=1.8$, $\sigma^{2}=3.1, \mathrm{n}=30 ; P=0.016$, Student's t-test) (Fig. 2). The average mass of $\mathrm{PaxG}^{+/-;}$Gli3+/-eyes $(19.3 \pm 0.8 \mathrm{mg}$, $s d=$ 4.1, $\left.\sigma^{2}=16.7, \mathrm{n}=25\right)$ was significantly less than that of wild-type eyes $(P<0.001$, Student's t-test $)$, but not significantly different to that of $\mathrm{Pax}^{+/-}$eyes. There was much greater variation than among eyes of the other genotypes (Fig. 2). Whereas only $1 / 24 \mathrm{Pax}^{+/-}$eyes fell within the range for wild-type eyes, $12 / 25$ of $\mathrm{Pax}^{+/-;} \mathrm{Gli3}^{+/-}$eyes fell within the wild-type range and 4/25 eyes weighed less than the smallest mass observed in the $\mathrm{Paxb}^{+/}$- group (Fig. 2). 

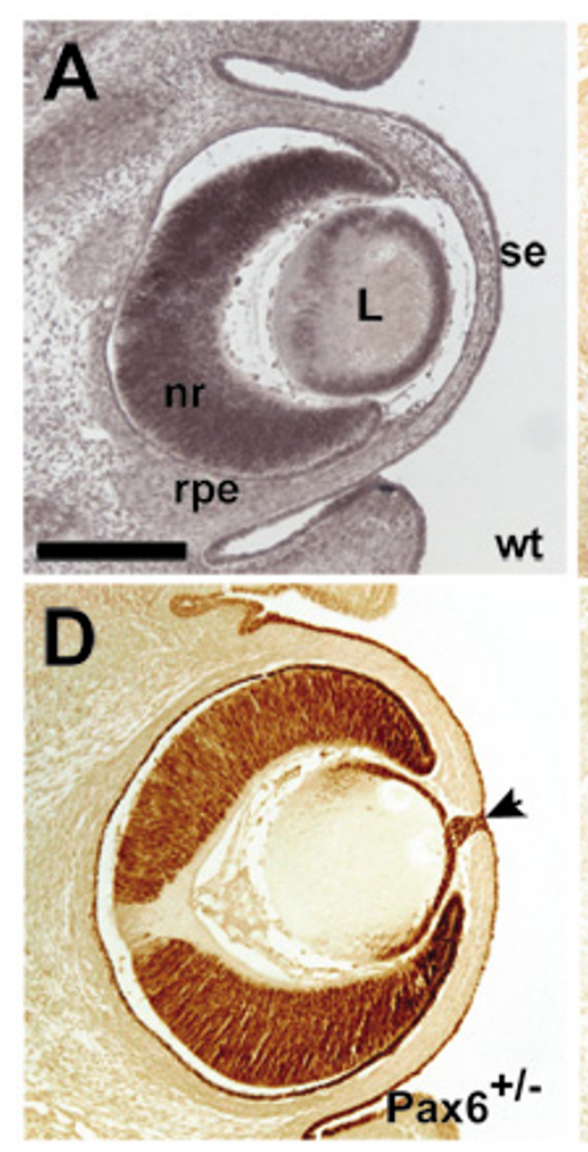
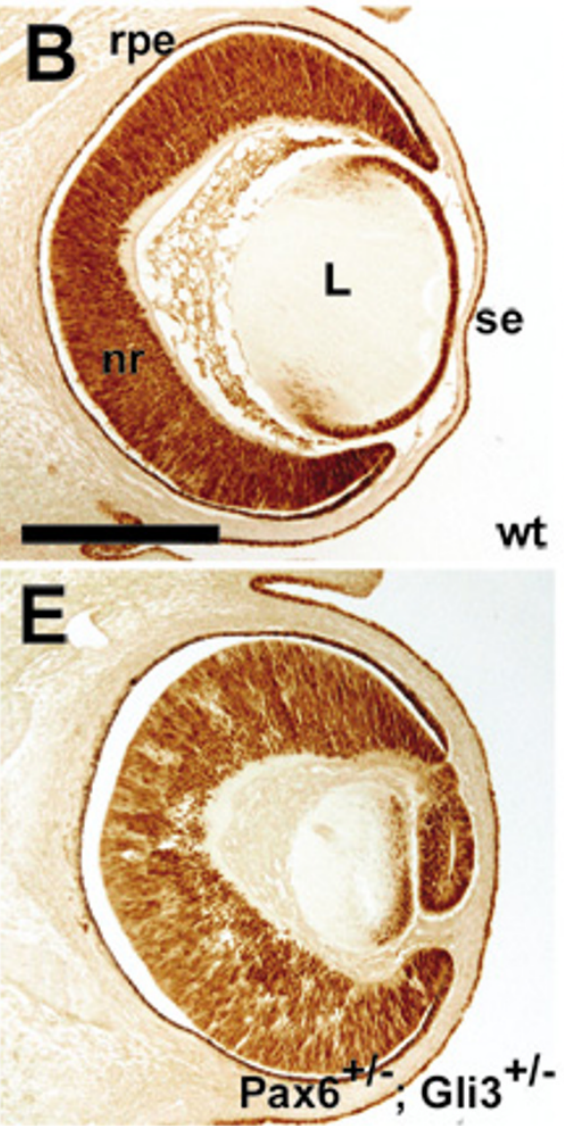

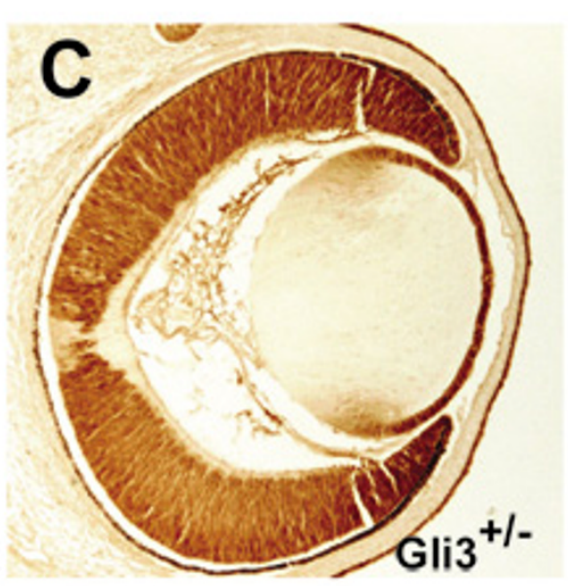

\section{Figure I}

(A) Gli3 mRNA expression in the developing eye at El4.5. mRNA expression is observed in the neural retinal, retinal pigment epithelium, lens and surface ectoderm. (B-E) Pax6 protein expression in (B) wild type, (C) Gli3+/, (D) Pax6 $6^{+/}$and (E) Pax6 $6^{+/}$; $\mathrm{Gli3}^{+/}$eyes. In wild type embyos (B), Pax6 is expressed in cells of the neural retina, lens epithelium and surface ectoderm. Gli3 $3^{+1}$ -embryos (C) show identical Pax6 expression to wild type with no overt retinal dysmorphology. Eyes of the developing Pax6 $6^{+/-}$ embryo (D) show a similar Pax6 expression to wild type but cells forming the persistent lens stalk (arrow) can be clearly seen to be Pax6 expressing. $\mathrm{Pax}^{+/-} ; \mathrm{Gli}^{+/-}$eyes (E) exhibit Pax6 expression localised to the neural retina, retinal pigment epithelium and lens epithelium but show overt distal retinal dysplasia. Rpe, retinal pigment epithelium; $n r$, neural retina; L, lens; se, surface ectoderm. Scale bar $=200 \mu \mathrm{m}$.

\section{Pax6+/-; Gli3+/- animals exhibit severe retinal abnormalities} No retinae from wild-type littermates of our mutant animals showed any overt abnormalities (Fig. 3A). The majority of Gli3+/- animals (22/25) showed no retinal dysplasia (Fig. 3B); a small proportion (3/25) did exhibit focal retinal hyperplasia (Fig. 3E). No retinal dysplasia was observed in any of the Pax $6^{+/-}$eyes studied (Fig. 3C) ( $\mathrm{n}=14) . \mathrm{Pax}^{+/-}$; Gli3 ${ }^{+/-}$retinae fell into 2 categories. 1$)$ Some retinae exhibited no dysplasia but were thinner than those of other genotypes (15/28) (Fig. 3D). 2) Some retinae were dysplastic (13/28) (Fig. 3F-H) with areas where lamination was completely disrupted with loss of any defined retinal organisation and mixing of the nuclear layers.
We compared retinal thicknesses in the positions shown in Fig. 4A in wild-type, $\operatorname{Pax6}^{+/-}$, Gli3+/- and $\mathrm{Pax6}^{+/-} ; \mathrm{Gli3}^{+/-}$ animals. Compound heterozygotes that had retinal dysplasia in the regions measured were excluded. Whole retinal thickness was significantly reduced in $\mathrm{Pax}^{+/ /-; G l i 3+/-}$ animals compared to their wild-type, $\operatorname{Pax} 6^{+/-}$and Gli3+/siblings, all of which had similar thicknesses (Fig. 4B).

We then examined which retinal layers were most affected in $\mathrm{Pax}^{+/-;}$Gli3+/- retinae. The adult neural retina is divided into 5 layers: the outer nuclear layer (ONL), the outer plexiform layer (OPL), the inner nuclear layer (INL), the inner plexiform layer (IPL) and the ganglion cell layer (GCL). We found that the thicknesses of both the ONL 


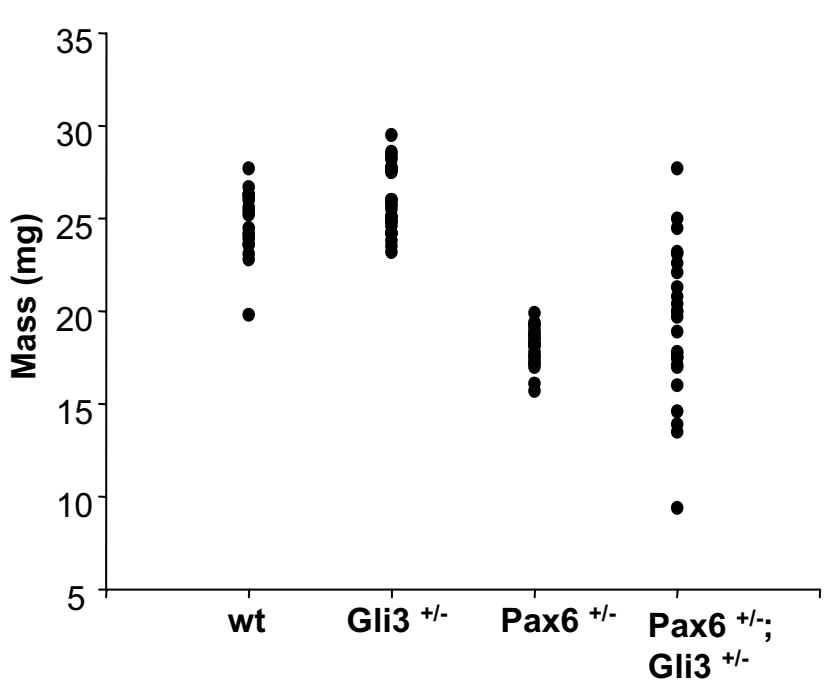

Figure 2

Masses of wild-type $(n=18), G l i 3^{+/-}(n=30)$, Pax6 $^{+/-}(n=24)$ and $\mathrm{Pax6}^{+/-} ; \mathrm{Gli3}^{+/-}(\mathrm{n}=25)$ adult eyes.

and INL of $\mathrm{Pax6}^{+/-} ; \mathrm{Gli3}^{+/-}$retinae were significantly reduced compared to those of the other genotypes (Fig. 4C,D). In some Pax6+/-; Gli3+/- retinae (3/21), the OPL was not discernible; where this layer was present, its average thickness was not significantly different to that of wildtype animals (Fig. 4E). Interestingly, the OPLs of both $\mathrm{Pax}^{+/-}$and Gli3 ${ }^{+/-}$retinae were thicker than those of wildtype and $\mathrm{Pax}^{+/-}$; Gli3 ${ }^{+/-}$animals (Fig. 4E). The IPL of the $\mathrm{Pax}^{+/-;}$Gli3+/- retina was significantly thinner than that of wild-type and Gli3+/- retinae, but was not significantly different to that of $\mathrm{Pax}^{+/-}$animals (Fig. 4F), which was itself significantly thinner than that of wild-types (Fig. 4F). As the GCL is only one cell thick, measurement was not done on this layer. We did not, however, observe any obvious defects in the GCL in any of the genotype groups. Overall, we concluded that the thicknesses of the retina and most of its layers are severely compromised in $\operatorname{Pax}^{+/-}$; Gli3 ${ }^{+/-}$ animals but not in $\mathrm{Pax}^{+/-}$or $\mathrm{Gli3}^{+/-}$siblings.

\section{Anterior segment and lens defects in $\mathrm{Pax6}^{+/-}$; $\mathrm{Gli}^{+/-}$ animals}

Consistent with previous studies [22], we observed lenscorneal adhesions with cellular bridges in $\mathrm{Pax}^{+/-}$embryonic (Fig. 1D) and adult eyes (Table 1). Lens-corneal adhesions were found with a similar incidence in $\operatorname{Pax}^{+/-}$; Gli3+/- eyes (Table 1). We observed several other types of abnormal contact in $\mathrm{Pax}^{+/-;}$; Gli3 ${ }^{+/-}$eyes, which were not found in wild-type, $\operatorname{Pax}_{6}{ }^{+/-}$or Gli3+/- eyes in our sample. These were common between the cornea and iris (Fig. $5 \mathrm{~A}, \mathrm{~B})$ but were also seen between retina and lens and iris and retina (Table 1 ). Some Gli3+/- eyes showed small
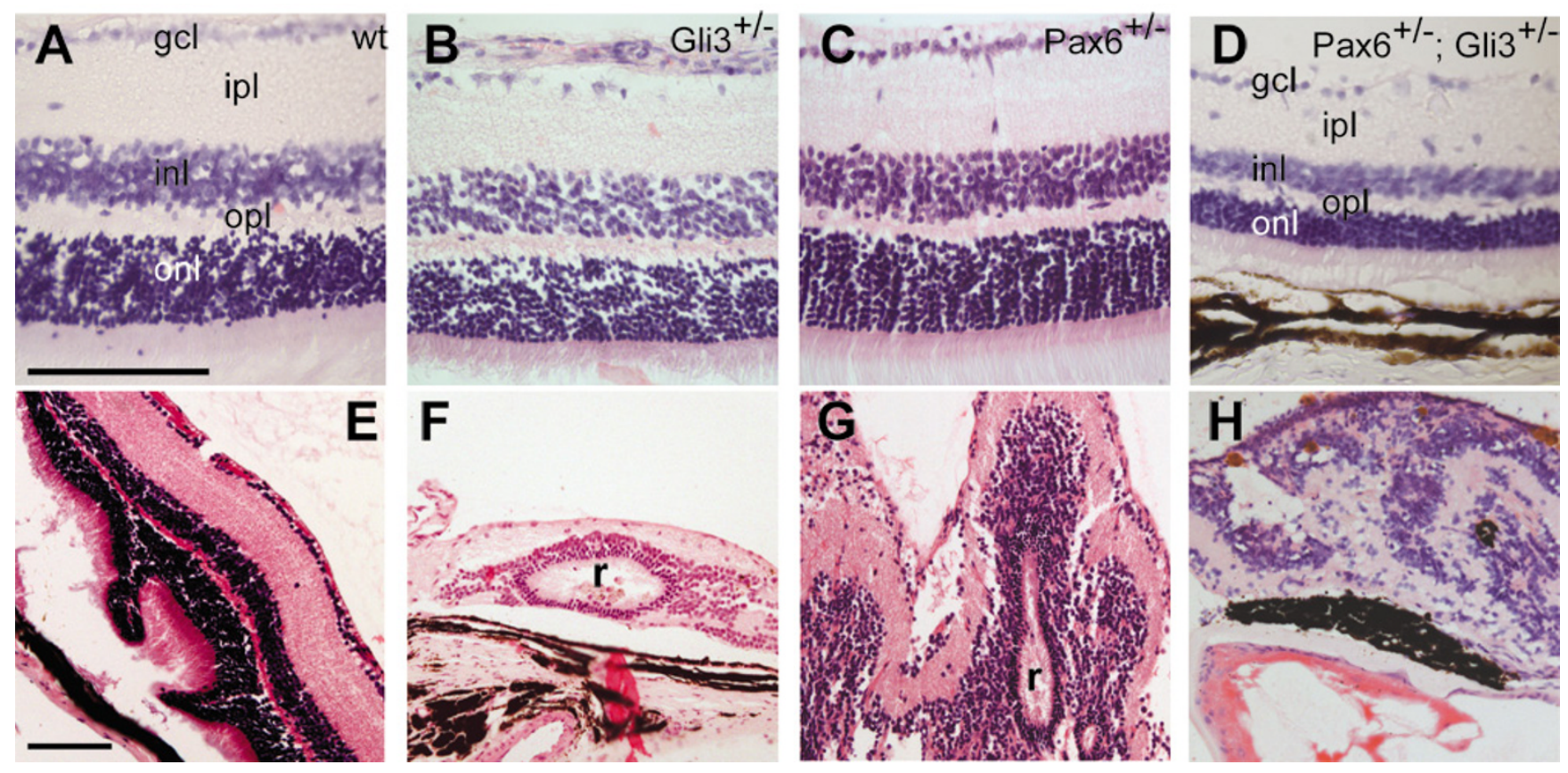

\section{Figure 3}

Retinal morphology of wild-type (A), Gli3+/- $(B, E), \mathrm{Pax6}^{+/-}(\mathrm{C})$ and Pax6+/-;Gli3+/- $(\mathrm{D}, \mathrm{F}-\mathrm{H})$ animals. Although a majority of Gli3+/retinae exhibit normal lamination (B), mild focal dysplasia is seen (E). Pax6 $6^{+/-}$; Gli3 ${ }^{+/}$retinal phenotypes include thinning of the retina (D) and dysplasia (F-H). gcl, ganglion cell layer; inl, inner nuclear layer; onl, outer nuclear layer; ipl, inner plexiform layer; opl, outer plexiform layer; $r$, rosette. Scale bars $=100 \mu \mathrm{m}$. 
A
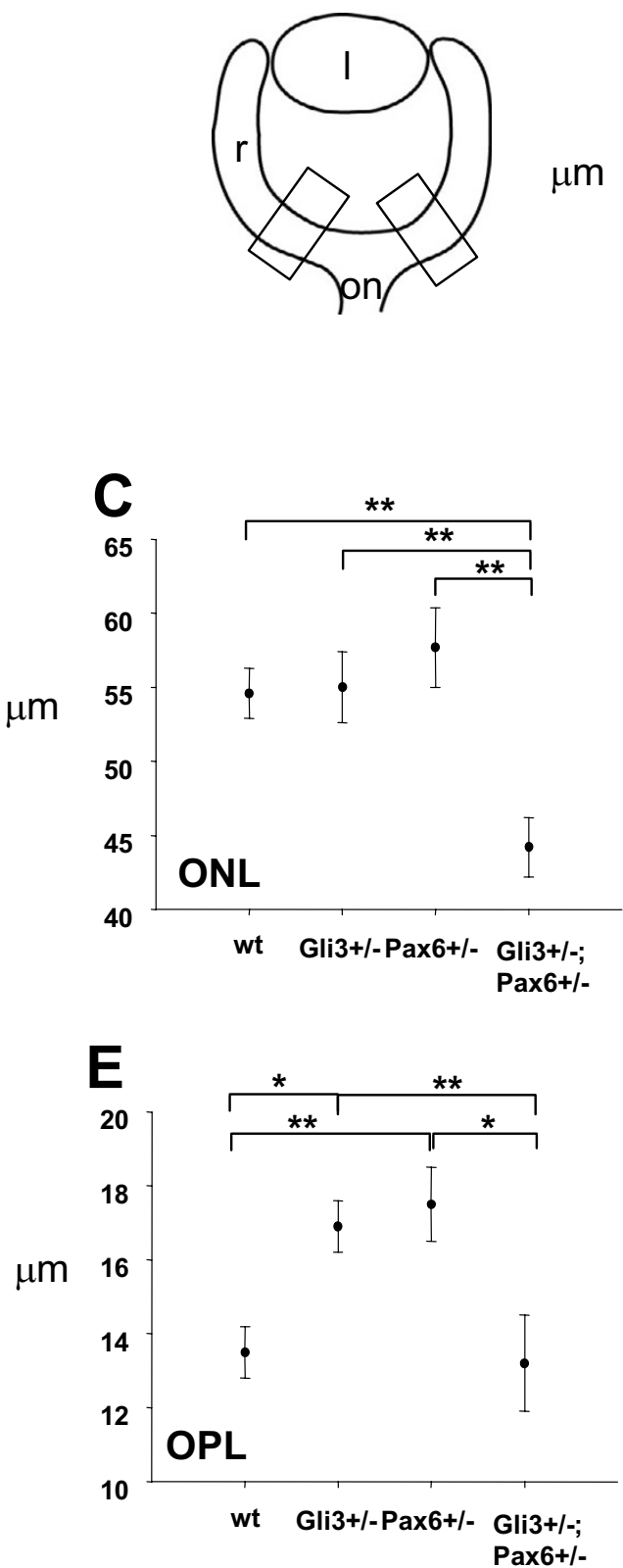

B

210

$\mu \mathrm{m}$

whole retina

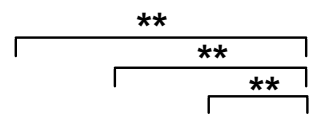

190

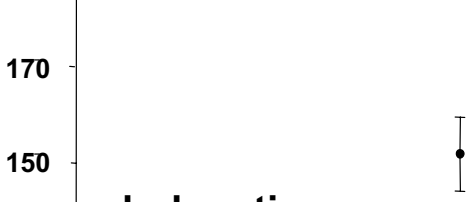

130
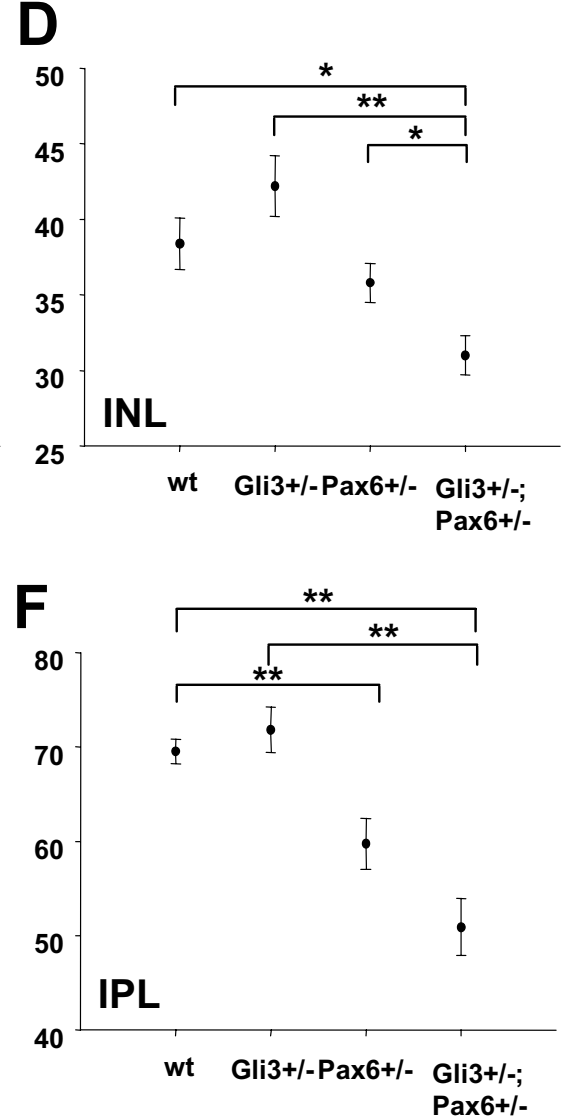

* $\mathrm{p}=<0.05$

$* * p=<0.001$

\section{Figure 4}

Retinal layer thickness in wild-type, Gli3 ${ }^{+/-}, \mathrm{Pax6}^{+/}$and $\mathrm{Pax6}^{+/-}$; Gli3 $3^{+/}$eyes. (A) Schematic representation of areas of retinal layer measurements in wild-type and mutant eyes. Measurement of retinal layers for (B) whole retinal thickness, (C) outer nuclear layer (ONL), (D) inner nuclear layer (INL), (E) outer plexiform layer (OPL), (F) inner plexiform layer (IPL) showing average thickness $(\mu \mathrm{m})(+/$ - s.e.m.) for each genotype group. Significant differences between genotypes are shown with brackets. I, lens; $r$, retina; on, optic nerve. $* P=<0.05$; $* * P=0.001$. 

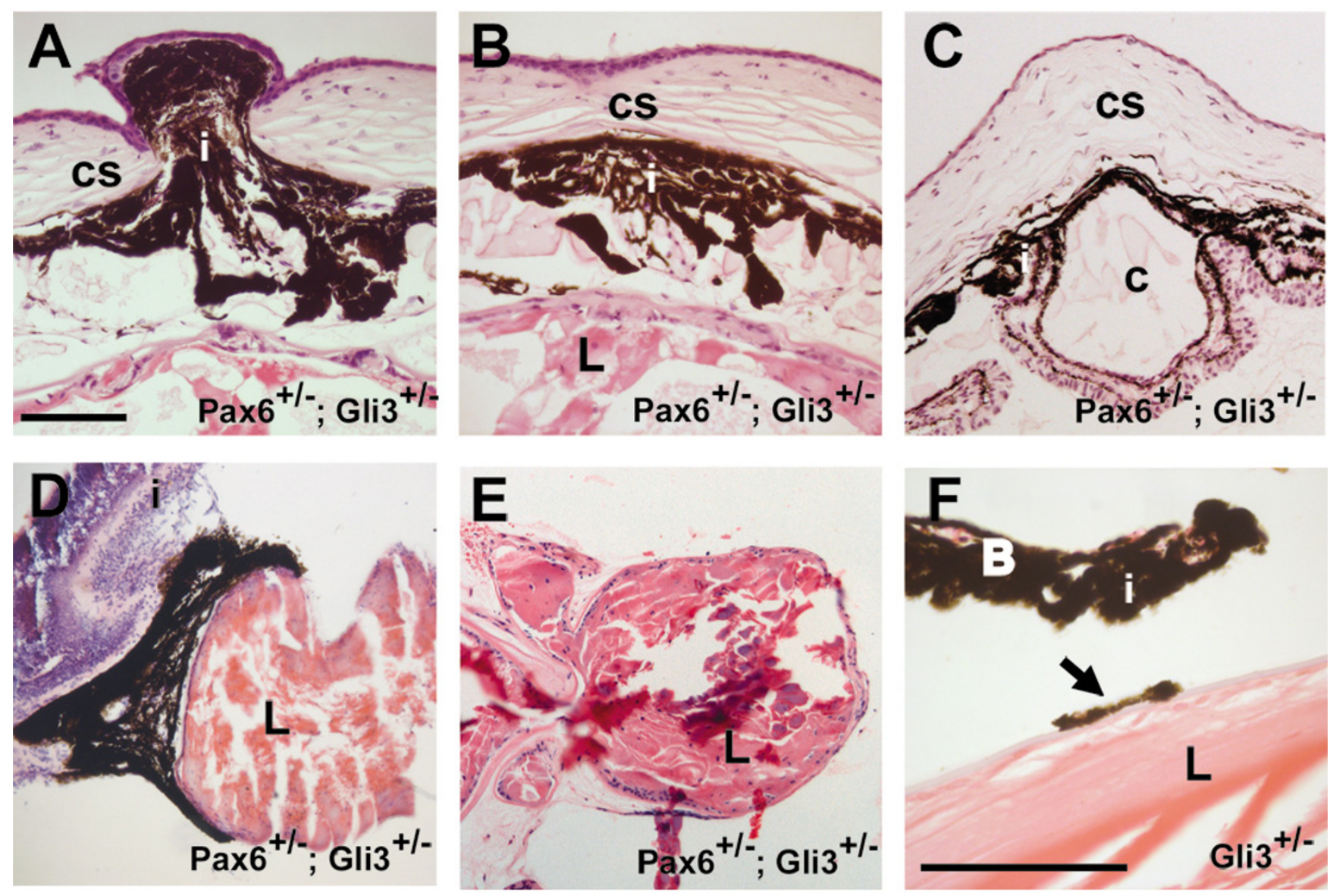

\section{Figure 5}

Anterior segment abnormalities in $\mathrm{Pax}^{+/-}$; Gli3 ${ }^{+/}$eyes. Abnormal contacts between cornea and iris (A-C), lens and cornea (E) and iris and lens (D) were observed in Pax6+/-; Gli3 ${ }^{+/-}$eyes. (A-C) Iris hyperplasia and formation of cyst-like structures involving iris, retina and cornea were also observed (C). (D, E) Some lenses of Pax6 $6^{+/-}$; Gli3 $3^{+/-}$animals were highly dysgenic. Some Gli3 ${ }^{+/-}$ animals had iris tissue attached to the lens (arrow in F). i, iris; cs, corneal stroma; L, lens; c, cyst. Scale bars = I00 $\mu \mathrm{m}$.

points of contact between the iris and lens (Fig. 5F; Table $1)$; these were not seen in $\mathrm{Pax}^{+/}$-eyes and were more frequent and extensive in $\mathrm{PaxG}^{+/-}$; Gli3+/- eyes (Table 1). We can not be sure of the exact nature of these contacts, but the fact that we did not observe them in wild-type eyes suggests that they reflect real defects in the interactions between different parts of the eye.

Many $\operatorname{Pax}^{+/-;}$Gli3+/- eyes exhibited highly dysgenic hyperplastic irises (12/28) (Fig. 5A,B), which were not observed

Table I: Incidence of abnormal contacts between different tissues in the eyes of wild-type, Gli3 ${ }^{+/-}$, Pax6 $6^{+/-}$and Pax6 $6^{+/-}$; Gli3 ${ }^{+/-}$animals.

\begin{tabular}{|c|c|c|c|c|c|c|}
\hline Genotype & Eyes $n=$ & Cornea-lens & Cornea-iris & Iris-Iens & Retina-lens & Iris-retina \\
\hline $\mathbf{W t}$ & 17 & $0 \%$ & $0 \%$ & $0 \%$ & $0 \%$ & $0 \%$ \\
\hline Gli3 $^{+/-}$ & 25 & $0 \%$ & $0 \%$ & $28 \%$ & $0 \%$ & $0 \%$ \\
\hline $\mathrm{Pax6}^{+/-}$ & 16 & $38 \%$ & $0 \%$ & $0 \%$ & $0 \%$ & $0 \%$ \\
\hline $\mathrm{Pax6}^{+/-}$; Gli3+/- & 28 & $36 \%$ & $64 \%$ & $68 \%$ & $39 \%$ & $7 \%$ \\
\hline
\end{tabular}


in any of the other genotype groups. Large cyst-like structures were observed between the iris, retina and overlying cornea (Fig. 5C) in one Pax6 $6^{+/-}$; Gli3 ${ }^{+/-}$eye. Some $\mathrm{Pax6}^{+/-}$; Gli3+/- animals (9/28) showed highly dysmorphic and dysgenic lenses, which were not observed in any of the other genotype groups (Fig. 5D, E).

\section{Corneal defects in Pax6+/-; Gli3+/- animals}

The corneal epithelium of the $\mathrm{Pax}^{+/}$eye has been reported to be thinner than normal and the corneal stroma is hypercellular $[21,22]$. We confirmed these findings in our samples (Fig. 6A,C). At the gross level, no differences were observed in the cornea between wild-type and Gli3+/- animals (Fig. 6A,B). Pax6 ${ }^{+/-;}$Gli3+/- animals exhibited similar corneal abnormalities to those observed in $\mathrm{Pax6}^{+/}$- animals (Fig. 6C,D).

Thicknesses of the corneal epithelium and corneal stroma, centrally and peripherally, were measured for the four genotype groups. There was no difference in both central or peripheral corneal epithelium thickness between wild- type and Gli3+/- eyes (Fig. 5E). As previously described [22], the corneal epithelium of $\operatorname{Pax}^{+/-}$eyes $(n=19)$ was significantly thinner than that of wild-type $(n=16)$ and Gli3+/- $(\mathrm{n}=27)$ eyes, both centrally and peripherally (Fig. $6 \mathrm{E}$; compared to wild-type and Gli3+/-: both $P<0.001$, Student's t-test). A similar result was observed in $\mathrm{Pax}^{+/-;}$; Gli3+/- eyes ( $\mathrm{n}=25$ ) (Fig. 6E; compared to wild-type and

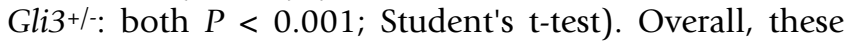
data suggest that loss of one copy of both Pax6 and Gli3 together does not create a corneal epithelium thinner than that resulting from loss of Pax 6 alone.

There was no difference in either central or peripheral corneal stromal thickness in $\mathrm{Pax}^{+/-}$or $\mathrm{Gli3}^{+/}$- eyes compared to wild-type eyes (Fig. 6F). The peripheral stroma of $\mathrm{Pax}^{+1}$ ; Gli3+/- eyes was, however, slightly thinner than that of wild-type and Gli3+/- eyes, while the central stroma was not different to that of wild-type eyes (Fig. 6F; compared to wild-type: $P=0.009$; compared to Gli3+/-: $P=0.016$; Student's t-tests). Thus, the mean stromal thickness (average of peripheral and central) of $\mathrm{Pax}^{+/-} ; \mathrm{Gli3}^{+/-}$eyes was

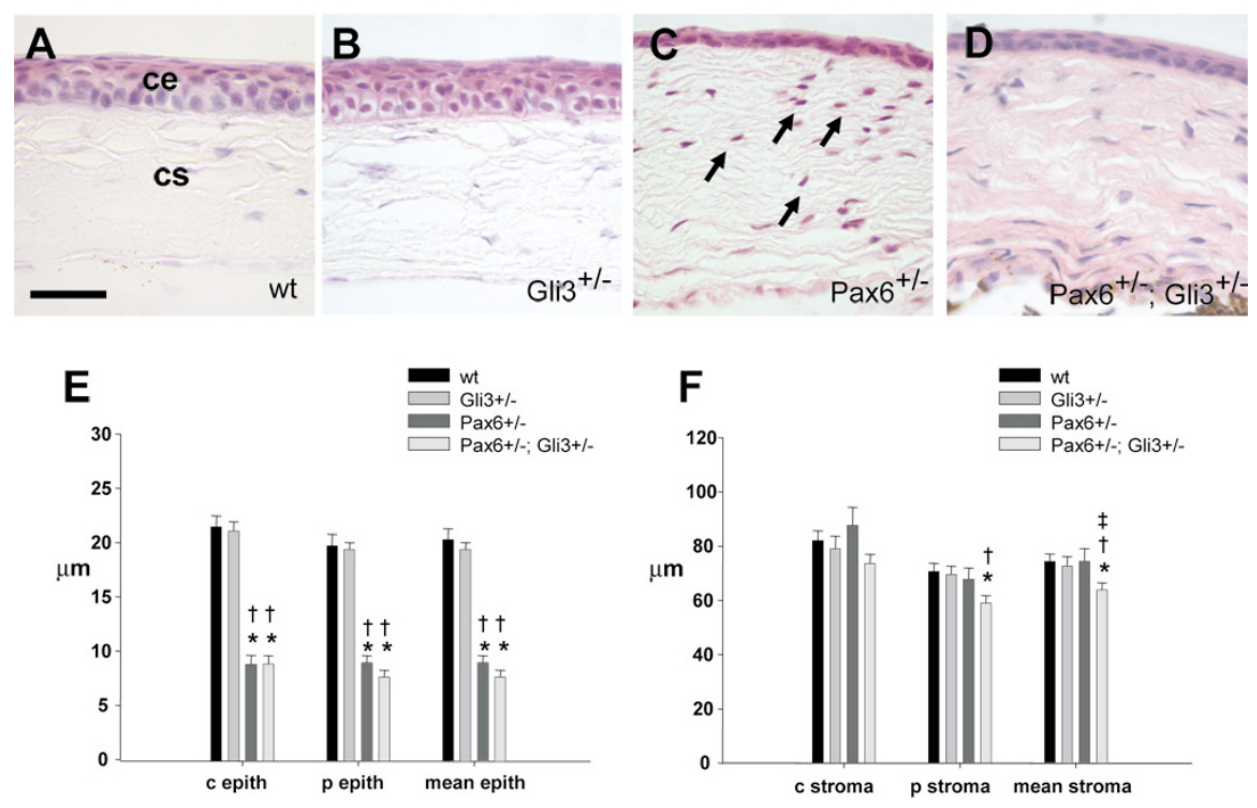

\section{Figure 6}

Corneal abnormalities in Pax6 $6^{+/-}$and Pax6 $6^{+/-}$; Gli3+/- eyes. Corneal morphology of (A) wild-type, (B) Gli3 $3^{+/-}$, (C) Pax6 $\mathrm{Pax6}^{+/-}$; Gli3 $3^{+/-}$animals. (C) Pax6+/- and (D) Pax6 $6^{+/-}$; Gli3+/- eyes have a thinner corneal epithelium and more hypercellular stroma (arrows in $\mathrm{C}$ ) than wild-type $(\mathrm{A})$ and $\mathrm{Gli3}+/-(\mathrm{B})$ eyes. Graphs show relative thicknesses of $(\mathrm{E})$ corneal epithelium and $(\mathrm{F})$ corneal stroma of the various genotype groups. The corneal epithelium of $\mathrm{Pax}^{+/-}$and $\mathrm{Pax} 6^{+/-} ; \mathrm{Gli3}^{+/-}$eyes was significantly thinner than that of wild-type and Gli3+/-eyes, both centrally and peripherally. The peripheral stroma of Pax6 $6^{+/-}$; Gli3 $3^{+/-}$eyes was thinner than that of wild-type and $\mathrm{Gli}^{+/-}$eyes, thus making the mean stromal thickness (average of peripheral and central) of Pax6 $6^{+/-}$; $\mathrm{Gli3}^{+/-}$ eyes significantly less than that of wild-type, $\mathrm{Pax}^{+/-}$and $\mathrm{Gli3} 3^{+/}$- eyes. $*=$ significantly different to wild-type; $\dagger=$ significantly different to Gli3 $3^{+/-} \ddagger=$ significantly different to $\mathrm{Pax}^{+/-}$. ce, corneal epithelium; cs, corneal stroma. Scale bar $=50 \mu \mathrm{m}$. 
significantly less than that of wild-type (Fig. 6F; $P=0.010$, Student's t-test), $\operatorname{Pax}^{+/-}$(Fig. 6F; $P=0.042$, Student's ttest) and Gli3+/- (Fig. 6F; $P=0.049$, Student's t-test) eyes.

\section{Discussion}

The importance of the transcription factors Pax6 $[16,18,19]$ and Gli3 $[4,9,10]$ in eye development is reflected in the severe eye phenotypes of homozygous mutants, which die around the time of birth. While it is well documented that loss of one copy of Pax 6 results in various eye defects [20-22], little is known about whether loss of one copy of Gli3 results in eye defects. Thus, in this study, we set out to characterise the morphology of the Gli3+/- eye. Furthermore, because both Pax6 and Gli3 are expressed in the optic cup/retina, lens and iris during development [5,18,27-29], we were also interested in whether Pax6 and Gli3 play mutually co-operative roles in eye formation by studying animals compound heterozygous for mutations in both Pax6 and Gli3.

No abnormality was observed in the majority of the Gli3+/ - eyes that we examined. Where abnormalities were seen, they were very mild. Gli3+/- eyes had a slightly higher mass than wild-type eyes as well as a thicker OPL compared to wild-type retinae. Retinal folding has been described previously in some neonatal Gli3+/- animals [4]. Overall, defects in Gli3+/- eyes are either not detectable or minor.

Animals compound heterozygous for mutations in both Pax6 and Gli3 exhibited unique and more severe eye defects than either $P a x 6^{+/-}$or Gli3 ${ }^{+/-}$animals or than would be predicted by addition of their phenotypes. As previously described [22], the mass of $\mathrm{Pax}^{+/-}$adult eyes was significantly smaller than that of wild-type eyes. The additional loss of one copy of Gli3 resulted in eyes with a wide range of eye mass, from some eyes with smaller mass than Pax $6^{+/-}$eyes to some eyes which fell within the wild-type range of eye mass.

A range of retinal phenotypes was observed in $\mathrm{Pax6}^{+/-}$; Gli3+/- eyes. Some Pax6+/-; Gli3+/- retinae were thinner than normal but exhibited normal lamination while others were severely dysgenic with considerable laminar dysmorphology. The severe retinal defects found in $\operatorname{Pax}_{6}^{+/-;}$Gli3 ${ }^{+1}$ - animals were never seen in either $\operatorname{Pax}^{+/-}$or $\mathrm{Gli}^{+/-}$animals. One mechanism by which Pax6 and Gli3 might cooperate during retinal development is through their actions in the Shh signalling pathway. This pathway is critical for normal eye development. Shh from the ventral midline of the early neural plate stage embryo is required for early patterning of the visual system [12]. Later, Shh is expressed in the developing retina [30] and has been shown to be important in photoreceptor development and retinal lamination [13,31]. Gli3 is essential for the transduction of Shh signalling: in the absence of Shh, the
Gli3 protein is cleaved proteolytically to produce a form that is thought to function mainly as a repressor [32]. Lowering the gene dosage of Gli3 can partially rescue the Shh-null phenotype [8], suggesting that reducing Gli3 levels allows the partial reactivation of Shh signalling pathways. It is possible, therefore, that a reduced level of Gli3 in otherwise wild-type cells (i.e. in Gli3+/- mice) mimics the effects of raising Shh levels. There is evidence that Shh suppresses Pax6 expression [23,33], and lowered Pax6 expression is known to affect eye development. While the loss of one copy of Gli3 (mimicking raised Shh signalling) might not lower Pax6 levels enough to create morphologically detectable defects if both alleles of Pax 6 are functional, levels might fall below a critical threshold in $\mathrm{PaxG}^{+/}$ ;Gli3+/- heterozygotes. Furthermore, there is evidence that Pax6 suppresses Shh expression [24-26] and so the decreased levels of Pax6 in the $\operatorname{Pax}^{+/-} ; \mathrm{Gli3}^{+/-}$heterozygotes might allow increased production of Shh, thereby further exacerbating the overstimulation of the Shh pathway. The mechanism by which reduced levels of the repressor form of Gli3 result in reduced Pax6 levels might involve loss of repression of intermediate transcription factors such as Pax2 and Vax1, that themselves repress Pax6 [11]. These possibilities are summarized in Fig. 7. While an interaction in Shh signalling seems likely, there are numerous other signalling pathways in which Gli3 and Pax6 might cooperate. A strong possibility is in fibroblast growth factor 8 (FGF8) signalling, since both Gli3 and Pax6 are known to regulate FGF8 expression $[29,34]$

Like the defects in the retina, abnormalities in the anterior segment of the $\mathrm{Pax}^{+/-} ; \mathrm{Gli3}^{+/-}$animals were more severe than those of either $\operatorname{Pax}^{+/-}$or $\mathrm{Gli3}^{+/-}$animals. $\mathrm{Pax}^{+/-}$; Gli3+/- animals had highly dysgenic lenses which were

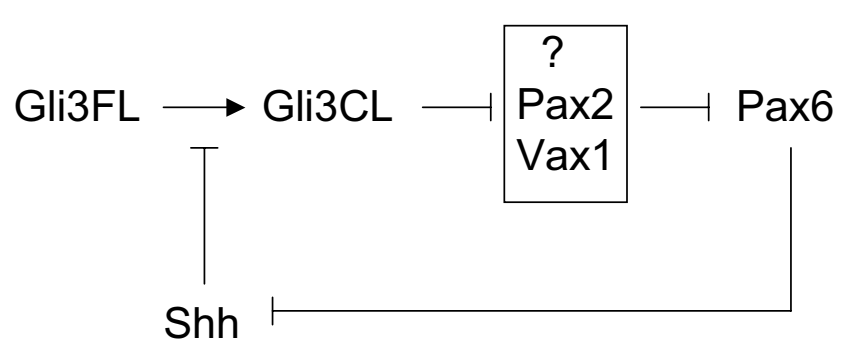

\section{Figure 7}

Summary of possible interactions between Gli3 and Pax6 in Shh signalling. The processing of $\mathrm{Gli} 3$ to its cleaved form (Gli3CL) from its full-length form (Gli3FL) is inhibited by Shh. Levels of Pax6 are regulated by levels of Gli3CL by a process of double repression, perhaps involving $\mathrm{Pax} 2$ and $\mathrm{Vaxl}$, such that lowering levels of Gli3CL lowers Pax6 levels. Pax6 negatively regulates Shh expression: thus, lowered Pax6 levels increase Shh's repression of Gli3CL production. 
never seen in $\mathrm{Pax}^{+/-}$or Gli3+/- animals. There were particularly high incidences of abnormal contacts involving the iris in $\mathrm{PaxG}^{+/-}$; Gli3+/- animals and, in contrast to the iris hypoplasia observed in $\mathrm{Pax}^{+/-}$animals, many $\mathrm{Pax6}^{+/-}$; Gli3+/- animals exhibited hyperplastic irises. Together these data suggest not only that the iris is sensitive to levels of Pax6 expression but that normal Gli3 expression may also be required, in conjunction with Pax6, for normal iris development to occur. Pax6+/-; $\mathrm{Gli3}^{+/-}$animals also showed thinning of the corneal epithelium and disorganisation of the corneal stroma, similar to that observed in $\mathrm{PaxG}^{+/-}$animals. Unlike Pax6 $\mathrm{C}^{+/}$and $\mathrm{Gli3}^{+/-}$animals, however, the peripheral corneal stroma was significantly thinner than in wild-types. As Gli3+/- animals showed no difference in the thickness of the corneal stroma, the reduction of Gli3 dosage alone does not affect stromal thickness but does so only in combination with reduced Pax6 dosage.

\section{Conclusion}

We have found that animals compound heterozygous for mutations in both Pax6 and Gli3 have eye abnormalities that are either not present in, or are more severe than, those present in animals heterozygous for mutations in either gene. Addition of the phenotypes of $\mathrm{Pax}^{+/-}$and Gli3+/- animals is insufficient to explain the severe phenotypes of the compound mutants. Our findings suggest that Gli3 and Pax6 cooperate during eye morphogenesis.

\section{Methods \\ Mice}

The Pax6+/- (Small eye, Sey) strain was maintained on a mixed $(\mathrm{C} 57 \mathrm{Bl} / \mathrm{Fa}, \mathrm{Ju} / \mathrm{Fa}$ and $\mathrm{JBT} / \mathrm{Jd})$ background as described previously [35]. The Gli3//-strain (Extra toes, $\mathrm{Xt}^{J}$ ) was maintained on an inbred CBA/Ca background. Animals wild-type at the Pax 6 and Gli3 loci, heterozygous for either mutation ( $\mathrm{Pax}^{+/-}$or $\mathrm{Gli3}^{+/-}$) and compound heterozygous for mutations in both genes $\left(\mathrm{Pax6}^{+/-} ; \mathrm{Gli3}^{+/-}\right)$were obtained by crosses between $\mathrm{Pax}^{+/-}$and Gli3+/- animals. 65 animals from 17 litters were analyzed. All comparisons were between wild type, $\mathrm{Pax6}^{+/-}$, Gli3+/- and $\mathrm{Pax6}^{+/-}$; Gli3+/ - siblings. Animals were killed by cervical dislocation; eyes were removed and some were weighed before fixing for histological preparation. All animal procedures were performed in accordance with Home Office (UK) legislation.

\section{Histology}

Eyes were fixed in either 4\% paraformaldehyde or Bouin's fluid overnight before dehydrating and processing to paraffin wax. Bouin's fluid was selected for tissue for morphometric analysis as it causes few artefacts of tissue fixation. Sections were cut at $10 \mu \mathrm{m}$ and stained with haematoxylin and eosin. Midsections through the eye containing the optic nerve were identified for morphometric retinal and corneal analysis.

\section{Genotyping}

Mutations in the Pax 6 gene were assessed as described previously [35]. Mapping of the mutant Gli3 ${ }^{X t J}$ allele has revealed a 51.5-kb deletion [36]. Using a multiplex PCR strategy [35], wild-type Gli3 and mutant Gli3 ${ }^{\mathrm{XtJ}}$ alleles were identified using the following primers: 580For 5' TACCCCAGCAGGAGACTCAGATTAG-3' and 580Rev 5'AAACCCGTGGCTCAGGACAAG-3'; C3For 5'GGCCCAAACATCTACCAACACATAG-3' and C3Rev 5'GTTGGCTGCTGCATGAAGACTGAC-3' producing products of $193 \mathrm{bp}$ and $580 \mathrm{bp}$ for the wild-type and mutant alleles respectively.

\section{Morphometric analysis}

Morphometric analysis of the retinal layers was performed only in eye sections where normal laminar morphology of the retina was maintained. Animals with eyes which were severely dysplastic were not included in this analysis. Transverse eye sections at the level of the optic nerve (medial section) were photographed with a digital camera at $\times 40$. The thicknesses of the whole retina as well as the thicknesses of the inner nuclear layer (INL), outer nuclear layer (ONL), inner plexiform layer (IPL) and outer plexiform layer (OPL) were measured using ImageTool ${ }^{\mathrm{TM}}$. Two separate measurements were taken on either side of the optic nerve (Fig. 4A) and averaged. Statistical comparison of layer thicknesses between genotype groups was carried out using Sigmastat ${ }^{\mathrm{TM}}$. Student's t-tests were used to compare layer thicknesses between genotype groups.

Analysis of corneal epithelial and stromal thickness was performed essentially as described previously [22]. Serial transverse sections of each eye were taken. The medial section ('Section 0') of each eye was determined. Analysis of corneal thickness was performed using a linear eye piece graticule on three medial and near-medial sections (Sections $0,-3$ and +3 ). The thickness (apical-basal depth) of the corneal epithelium, stroma and the whole cornea were measured separately at the centre and periphery of the cornea on all three sections for each eye. Data from central and peripheral regions were combined to obtain overall mean thickness of corneal epithelium and stroma in each eye. Statistical comparison of corneal thickness between genotype groups was carried out using Sigmastat ${ }^{\mathrm{TM}}$. Student's t-tests were used to compare corneal layer thickness between genotype groups.

\section{Immunohistochemistry}

Slides were microwaved in $10 \mathrm{mM}$ sodium citrate to achieve maximal antigen retrieval before addition of primary antibody. Mouse monoclonal anti-Pax6 antibody (1:100) was obtained from the Developmental Studies Hybridoma Bank (University of Iowa, Department of Biological Sciences, Iowa City, IA 52242). Signal was 
enhanced using the Dako $\mathrm{ABC}$ Kit and visualised with diaminobenzidine (DAB).

\section{RNA in-situ hybridisation}

A 611 base pair fragment comprising nucleotides 5601170 of the mouse Gli3 cDNA (a gift from T. Theil) was PCR amplified and subcloned into a pGEM-Teasy vector (Promega). The plasmid was linearized with SpeI and transcribed with T7 RNA polymerase. Non-radioactive RNA in-situ hybridisation on paraffin wax-embedded sections was carried out using a protocol described previously [27].

\section{Abbreviations \\ GCPS Greig cephalopolysyndactyly}

\section{DAB diaminobenzidine}

FGF8 fibroblast growth factor 8

GCL ganglion cell layer

INL inner nuclear layer

IPL inner plexiform layer

ONL outer nuclear layer

OPL outer plexiform layer

PHS Pallister-Hall Syndrome

Shh Sonic hedgehog

Xt extra-toes

\section{Authors' contributions}

PZ and JQ designed and carried out most of the experiments, MC participated in the quantitative analysis, JT carried out in situ hybridizations, IS participated in the design and carrying out of genotyping, DP participated in the analysis and writing of the manuscript.

\section{Acknowledgements}

We thank Katy Gillies, Lynsay Watson and Duncan McNeil for technical support. This work was supported by the National Eye Institute (F32 EY 13929, PAZ), Scottish Hospitals Endowments Research Trust (RG46/03, JMC), Wellcome Trust (GR074I27MA, JMC; 07I5I3, JCQ, DJP) and Medical Research Council (G0I00628, TIS, DJP). JT was supported by a Nuffield Foundation Undergraduate Research Bursary and a Wellcome Trust Vacation Scholarship.

\section{References}

I. Vortkamp A, Gessler M, Grzeschik KH: GLI3 zinc-finger gene interrupted by translocations in Greig syndrome families. Nature 1991, 352:539-40.
2. Kang S, Graham JM, Olney AH, Biesecker LG: GLI3 frameshift mutations cause autosomal dominant Pallister-Hall syndrome. Nat Genet 1997, 15:266-8.

3. Vortkamp A, Franz T, Gessler M, Grzeschik KH: Deletion of Gli3 supports the homology of the human Greig Cephalopolysyndactyly Syndrome (GCPS) and the mouse mutant extra toes (Xt). Mammalian Genome 1992, 3:46I-463.

4. Johnson DR: Extra-toes: a new mutant gene causing multiple abnormalities in the mouse. J Embryol Exp Morphol 1967, 17:543-8I.

5. Hui CC, Slusarski D, Platt KA, Holmgren R, Joyner AL: Expression of three mouse homologs of the Drosophila segment polarity gene cubitus interruptus, Gli, Gli-2, and Gli-3, in ectoderm- and mesoderm-derived tissues suggests multiple roles during postimplantation development. Dev Biol 1994, 162:402-13

6. Zaki PA, Martynoga B, Price DJ: The role of hedgehog and Gli signalling in telencephalic development. In Shh and Gli signalling and development Edited by: Howie S, Fisher C. Landes Bioscience; 2005.

7. Tyurina OV, Guner B, Popova E, Feng J, Schier AF, Kohtz JD, Karlstrom RO: Zebrafish Gli3 acts as both an activator and repressor in Hedgehog signalling. Dev Biol 2005, 282:550-70.

8. Litingtung $Y$, Chiang C: Specification of ventral neuron types is mediated by an antagonistic interaction between Shh and Gli3. Nature Neuroscience 2000, 3:979-85.

9. Franz $T$, Besecke A: The development of the eye in homozygotes of the mouse mutant Extra-toes. Anat Embryol (Berl) I99I, 184:355-61.

10. Kondoh H: Development of the Eye. In Mouse development: Patterning, Morphogenesis and Organogenesis Edited by: Janet Rossant. San Diego, San Fransisco, New York, Boston, London, Sydney, Tokyo: Academic Press; 2002.

II. Furimsky M, Wallace VA: Complementary Gli activity mediates early patterning of the mouse visual system. Developmental Dynamics 2006, 235:594-605.

12. Chiang C, Litingtung Y, Lee E, Young KE, Corden JL, Westphal H, Beachy PA: Cyclopia and defective axial patterning in mice lacking Sonic hedgehog gene function. Nature 1996, 383:407-13.

13. Wang YP, Dakubo G, Howley P, Campsall KD, Mazarolle CJ, Shiga SA, Lewis PM, McMahon AP, Wallace VA: Development of normal retinal organization depends on Sonic hedgehog signaling from ganglion cells. Nat Neurosci 2002, 5:83I-2.

14. Wawersik S, Maas RL: Vertebrate eye development as modeled in Drosophila. Hum Mol Genet 2002, 9:917-25.

15. Ashery-Padan R, Gruss P: Pax6 lights-up the way for eye development. Curr Opin Cell Biol 200I, I3:706-14.

16. Hill RE, Favor J, Hogan BLM, Ton CCT, Saunders GF, Hanson IM, Prosser J, Jordan T, Hastie ND, Vanheyningen V: Mouse small eye results from mutations in a paired-like homeobox- containing gene. Nature 1991, 354:522-525.

17. Prosser J, van Heyningen V: PAX6 mutations reviewed. Hum Mutat 1998, II:93-108.

18. Grindley JC, Davidson DR, Hill RE: The role of Pax-6 in eye and nasal development. Development 1995, I 2 I: | 433-42.

19. Hogan BL, Horsburg G, Cohen J, Hetherington CM, Fisher G, Lyon MF: Small eyes (Sey): a homozygous lethal mutation on chromosome 2 which affects the differentiation of both lens and nasal placodes in the mouse. J Embryol Exp Morphol 1986, 97:95-II0.

20. Baulmann DC, Ohlmann A, Flugel-Koch C, Goswami S, Crekl A, Tamm ER: Pax6 heterozygous eyes show defects in chamber angle differentiation that are associated with a wide spectrum of other anterior eye segment abnormalities. Mech Dev 2002, I I 8:3-I7.

21. Davis J, Duncan MK, Robison WG Jr, Piatigorsky J: Requirement for Pax6 in corneal morphogenesis: a role in adhesion. J Cell Sci 2003, I I 6:2157-67.

22. Ramaesh T, Collinson JM, Ramaesh K, Kaufman MH, West JD, Dhillon B: Corneal abnormalities in Pax6+/- small eye mice mimic human aniridia-related keratopathy. Invest Ophthalmol Vis Sci 2003, 44: $187 \mid-8$

23. Macdonald R, Barth KA, Xu Q, Holder N, Mikkola I, Wilson SW Midline signalling is required for $P a x$ gene regulation and patterning of the eyes. Development 1995, I 2 1:3267-78. 
24. Stoykova A, Treichel D, Hallonet M, Gruss P: Pax6 modulates the dorsoventral patterning of the mammalian telencephalon. J Neurosci 2000, 20:8042-50.

25. Grindley JC, Hargett LK, Hill RE, Ross A, Hogan BL: Disruption of PAX6 function in mice homozygous for the Pax6Sey-I Neu mutation produces abnormalities in the early development and regionalization of the diencephalon. Mech Dev 1997, 64: $111-26$

26. Pratt T, Vitalis T, Warren N, Edgar JM, Mason JO, Price DJ: A role for Pax6 in the normal development of dorsal thalamus and its cortical connections. Development 2000, I 27:5167-78.

27. Collinson JM, Quinn JC, Hill RE, West JD: The roles of Pax6 in the cornea, retina, and olfactory epithelium of the developing mouse embryo. Dev Biol 2003, 255:303-12.

28. Walther C, Gruss P: Pax-6, a murine paired box gene, is expressed in the developing CNS. Development 1991, I I 3:1435-49.

29. Aoto K, Nishimura T, Eto K, Motoyama J: Mouse GLI3 regulates Fgf8 expression and apoptosis in the developing neural tube, face, and limb bud. Dev Biol 2002, 25I:320-32.

30. Jensen AM, Wallace VA: Expression of Sonic hedgehog and its putative role as a precursor cell mitogen in the developing mouse retina. Development 1997, 124:363-7|.

31. Black GC, Mazerolle C], Wang Y, Campsall KD, Petrin D, Leonard BC, Damji KF, Evans DG, McLeod D, Wallace VA: Abnormalities of the vitreoretinal interface caused by dysregulated Hedgehog signaling during retinal development. Hum Mol Genet 2003, I 2:3269-76

32. Ruiz i Altaba A: Gli proteins encode context-dependent positive and negative functions: implications for development and disease. Development 1999, I 26:3205-16

33. Li H, Tierney C, Wen L, Wu JY, Rao Y: A single morphogenetic field gives rise to two retina primordial under the influence of the prechordal plate. Development 1997, 124:603-15.

34. Reza HM, Yasuda $K$ : The involvement of neural retina pax6 in lens fiber differentiation. Dev Neurosci 2004, 26:3 I8-27.

35. Quinn JC, West JD, Hill RE: Multiple functions for Pax6 in mouse eye and nasal development. Genes Dev 1996, 10:435-46.

36. Maynard TM, Jain MD, Balmer CW, LaMantia AS: High-resolution mapping of the Gli3 mutation extra-toes reveals a 5 I.5-kb deletion. Mamm Genome 2002, 13:58-61.
Publish with Bio Med Central and every scientist can read your work free of charge

"BioMed Central will be the most significant development for disseminating the results of biomedical research in our lifetime. "

Sir Paul Nurse, Cancer Research UK

Your research papers will be:

- available free of charge to the entire biomedical community

- peer reviewed and published immediately upon acceptance

- cited in PubMed and archived on PubMed Central

- yours - you keep the copyright 